\title{
Techniques of High Tibial Osteotomy: A Review
}

\author{
Mohammad Jawed Aqil, Liyong Gang*, Abdul Qadir Nawabi, Jinan Wei, Nasir Ahmad Haidari \\ College of Medicine, Southeast University, Nanjing, China \\ Email: ${ }^{*} 13601454503 @ 163 . c o m$
}

How to cite this paper: Aqil, M.J., Gang, L.Y., Nawabi, A.Q., Wei, J.N. and Haidari, N.A. (2020) Techniques of High Tibial Osteotomy: A Review. Open Journal of Orthopedics, 10, 93-109. https://doi.org/10.4236/ojo.2020.105011

Received: March 15, 2020

Accepted: May 10, 2020

Published: May 13, 2020

Copyright (อ 2020 by author(s) and Scientific Research Publishing Inc. This work is licensed under the Creative Commons Attribution International License (CC BY 4.0).

http://creativecommons.org/licenses/by/4.0/

(c) (i) Open Access

\begin{abstract}
Main intention of the research is to understand about significance of techniques associated with HTO. This research reviewed the techniques of high tibial osteotomy namely high tibial osteotomy, open wedge high tibial osteotomy, closedhigh tibial osteotomy. Patients who are suffering from knee arthritis, high tibial osteotomy assists to prevent or delay the requirement for total or partial replacement of knee to preserve damaged tissue of joint. High tibial osteotomy technique is mainly suitable for active and young patients with knee osteoarthritis. Age plays a main factor in success rate of high tibial osteotomy technique. It could be done in open wedge or closed wedge high tibial osteotomy. For some cases, surgery could be done in combined method (open wedge and closed wedge high tibial osteotomy). When compared with clinical outcomes of closed wedge high tibial osteotomy and open wedge high tibial osteotomy, open wedge high tibial osteotomy performs well in reducing the pain, duration of weight-bearing and return to normal life as soon as possible.
\end{abstract}

\section{Keywords}

High Tibial Osteotomy, Open Wedge High Tibial Osteotomy, Knee Osteoarthritis, Closed Wedge High Tibial Osteotomy

\section{Introduction}

Joint in knee is main and complicated joint for motion and load, entailing the PF (patellofemoral) joint and TF (tibiofemoral) joint. Joint in knee stability is mostly dependent on interacting cartilaginous and ligamentous meniscus, structures and some tendons and muscles. Loads given on tibiofemoral joint are sometimes over BW (body weight) during every day activities and average high forces for resultant were peak when climbing down the stair (346 percent BW), climbing up the stairs (316 percent BW) and walking level (261 percent BW). Force distribution between medial and lateral is relied on TF alignment and differs within various tasks like weight-bearing [1]. At the time of walking gait, distribution of 
load between medial and lateral differs based on tibia [2] [3]. Nearly 75 percent of load in joint passes through plateau of medial tibial at the time of single-leg stance [4].

Nowadays, OA (Osteoarthritis) is commonly seen among adults like joints disease all over the globe. It is functioned by progressive articular cartilage loss come with novel formation of bone and mostly synovial proliferation would culminate in joint function loss, pain and disability [5]. A report given by world health organization about global load of disease reveals that knee osteoarthritis (KO) mostly to become fourth main major reason of disability among females and eighth most reason among males [6].

$\mathrm{KO}$ is most commonly seen in India when compared with western countries and also found one of major disability like any other chronic ones. $\mathrm{KO}$ is seen commonly seen in elderly person but nowadays even it is affecting person age less than fifty years [7]. Both local factors such as deformity in the joint and weakness in the muscle and systemic factors like genes, sex and age seem to major factor among individual joints which develop the disease. Particular aetiological factors are not known; at the same time also encompass failure of internal remodelling system controlled by chrondrocyte, mechanical overloading and additional cartilaginous factors like vascular changes or synovial changes [8]. High tibial osteotomy (HTO) is surgical technique accepted for medial knee arthrosis compartment in young patients. HTO's biomechanical principle which redistributes the forces of weight bearing from compartment of worn towards lateral compartment thus relieves pain and lowers the progression of disease. Choosing suitable patients, accurate surgical technique and extensive planning for pre-operation are needed for successful result [9].

$\mathrm{KO}$ is general clinical disease which affects person above 65. Major reasons of $\mathrm{KO}$ are overwork, knee degenerative diseases, postural errors and more. Deformities of knee, which represent one of main reason of KO, were not taken seriously. It could cause damage in force line at lower limb, surface wear of knee cartilage and collapse of tibial plateau which lead to KO. Most significant method of treatment in clinic is arthroplasty of knee. Such method is traumatic, expensive and complications prone and revision of artificial joint after surgery. At the same time, complete application of HTO is tissue regeneration of chronic distraction and external fixation assisted in computer for treating severe KA has effective and exact control on the angle of HTO, patient recover quickly, low volumes in bleeding, postoperative ability of adjustment, surgical trauma at low levels and so on [10].

HTO is best option in physically active and younger patient with loss of symptomatic cartilage and malalignment of varus [11]. Though, HTO has revision rate of nearly thirty percent at 10 years, attributable either to arthrosis development in patellofemoral or laternal compartments or arthrosis progress in compartment of medial tibiofemoral [11] [12].

Presently only option for revision for failed HTO is TKA (total knee arthro- 
plasty). When compared with primary TKA, inferior and equivalent results [13]. Other than this, active patients at young age like require revision post-HTO and at the same time primary TKA also link with main levels of not satisfaction and higher rates of revision [14] [15] [16]. UKA (unicompartmental KA) are best alternative among patients with arthrosis of TF compartment and they are not included because of modified mechanical alignment, distorted tension of soft tissue in post-HTO and abnormal obliquity of tibial joint line [17] [18]. Below Figure 1 illustrates inclusion and exclusion criteria of articles searched using various medical databases.

\section{Literature Review}

A search was carried out using electronic database like Medline, PudMed, Scopus, and Web of science and Embase. Key words used for searching are high tibial osteotomy, open wedge high tibial osteotomy, closed wedge high tibial osteotomy, healing after high tibial osteotomy, knee osteoarthritis. After the initial search of articles, eligible articles were screened cautiously for review.

\subsection{HTO}

HTO was found to be attractive and successful option for treatment particularly for active and young patients with medical compartment KO. It transforms the bearing of weight axis to comparatively not affected lateral compartment [18] [19] [20] [21]. There are two fundamental techniques are mostly carried out medial OWHTO and lateral closing wedge HTO [22] [23] and closed-wedge HTO [24]. Numerous investigators [25] [26] [27] [28] have pointed that HTO is seen as surgical treatment option in medial femorotibial osteoarthritis. On the other hand, Merchan [29] found that HTO do not impact survival or function of TKA for long run. Further [13] [30]-[34] also studied about patients who underwent HTO technique.

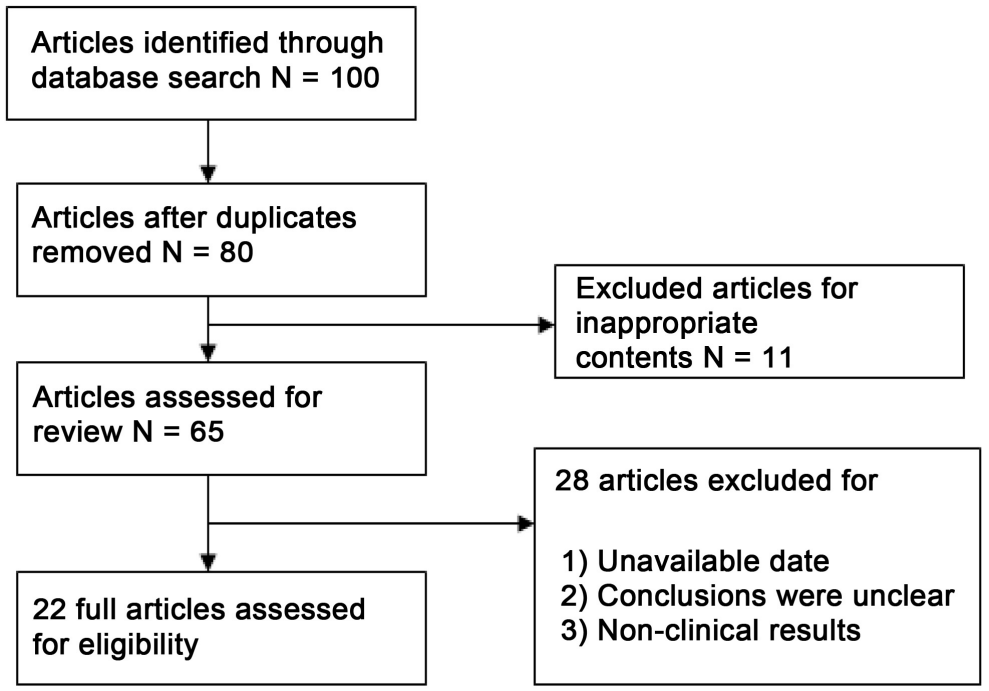

Figure 1. Inclusion and exclusion criteria of articles. 
Malahias et al. [35] pointed out that patients with deficient varus angulated knee-anterior cruciate ligament (ACL) require isolated HTO as well as extra ACL reconstruction. From the findings of the investigation, it was found that ACL reconstruction and one stage HTO is efficient and safe procedure to treat the patients who suffer from symptomatic varus osteoarthritis to combine with instability of anterior knee. Cao et al. [36] and Takeuchi et al. [37] mentioned that HTO indicated an enhanced sign for active patients with best motion range of knee. Even though there are no main variances in clinical results between HTO and UKA at 2-years and 12 months follow-up, benefits of HTO is to preserve joint of knee as soon as probable, great corrective impact of mechanical axis and postponement or avoidance in replacing the knee [22] [38] [39].

Weiye et al. [40] studied about male patient aged 48 years with KO occurred by long-term varus of genu which outcome in both knees pain, particularly in right knee. Pain in the right knee was intensified for two years and admitted in hospital for pain of left knee for 1 month. It was found that for treating the KO patients with varus of genu, HTO combination, regeneration of tissue in chronic distraction and computer-assisted adjustment in technology of external fixation have best impact on correcting the deformity of genu varus and recovery of minimal line of limb force. Such method for treatment is conductive to prevent infection of post-operative and avoid secondary trauma occurred by removing the plates of internal fixation.

According toSarwar et al. [41] HTO is verified to have high rate in success and low rate in complication with the occurrence of non-union as minimal as $0-4.4$ percent. 80 percent of patients bring back their regular schedule after 1 year, $2 / 3 \mathrm{rds}$ of them as demanding level or higher than levels of preoperative. It is substitute procedure for arthroplasty of knee in active, young patients with malaligned knee induced degeneration of medial compartment. Substantial result in long term is direct outcome of suitable in selection of patient, exact surgical fixation and technique and sufficient postoperative management. It was claimed that HTO is efficient for reducing the pain and function of knee improvement in patients with knee's medial compartmental OA; on the other hand, no osteotomy technique found higher to others and no proper evidence that HTO is more efficient when compared with non-operative treatment or UKR [42].

Functional outcome and physical activity among patients who present with medial compartment KO. 174 patients who underwent HTO are estimated after 47.9 days follow-up periods. Physical activities and functional outcome scored based on published rating systems. 81.6 percent of patients were satisfied with surgery outcome, 64.3 percent of the patients opined that they would able to perform their daily activities after surgery without any decline or restriction in performance. 58.6 percent of the patients able to resume physical activities at levels of pre-operative. Further few patients could continue exercises. From the findings of the research, it was obvious that HTO permit patients to continue their physical activities with symptomatic osteoarthritis of KO medial compart- 
ment, outcome in enhancing clinical conditions and as a result in their recreational activities and every day working activities [43].

Patient with increased age was interlinked with higher rates of failure after surgery of HTO [44] [45] [46]. Hui et al. [7] compared patients older and younger than fifty years and identified hazard ratio of 3.7 percent among patients above 50 years. When carrying out multivariate analysis, age was found to be main factor of patients who undergo arthroplasty with 8 percent high risk for increasing age at every one year. However it is not clear that what cutoff of age could be adopted, high rise in rates of failures likes to happen in age group of 50 to 60 years. Older patients who decide to do HTO surgery have to consider all risk factors. It was noted that impact of age on revision when compared with OA preoperative diagnosis is very less and therefore severity of the disease and physiological age are better signs of revision instead of preferring complete biological age.

Pannell et al. [47] identified 1576 procedures from 2000 to 2014, among these 358 procedures were changed to arthroplasty during ten years. It was found that older patients who undergone arthroplasty after surgery HTO had great frequency of hypertension and great likelihood of getting comorbidity. Furthermore, it was noted that patients were 8 percent would need arthroplasty for every other year in age. It was noticed that female patients were under high conversion risk to arthroplasty than male patients. Apart from these, survivorship at 10 and 5 years was 56 percent and 80 percent respectively and failure rate's median time was 5.1 years. Long-term survival was seen among selected patients who undergone HTO. Careful observations have to be provided to patient sex, age and KO when patients decide to undergo this procedure.

Kumar et al. [48] conducted single centre and interventional research was performed on 60 patients were radiologically and clinically diagnosed as varus deformity KO. After assessment of proper pre-operative one, patient had undergone HTO. Outcomes in terms of clinically were estimated with functional score and score of knee society. At regular intervals, follow-up was done for patients during third, sixth and $12^{\text {th }}$ month. Mean functional score and knee score of preoperative mean for patients' prior operation were 53.22 percent and 54.3 percent respectively. Functional score and knee score at 1 year was found to be 81.5 percent and 82.3 percent respectively. Thus comparison score of postoperative and pre-operative indicated statistically important enhancement in functional and knee society score. From the findings of the investigation, it was found there was major rise in functional score and knee score after HTO for patients of varus deformity KO. Thus HTO must be suggested for degenerative arthritis treatment of knee in active, young patients for symptomatic enhancement and activity levels maintenance.

HTO is adopted for physically active and young patients with KO. Such patients have huge hope, encompassing RTS (Return to sport). It was identified that more than 8 patients out of 10 after HTO, return to sport and among them most of them RTO within six months. A move from participation in high and intermediate effect sports to intermediate and low effect scores are predicted. 
Thus it was clear from the outcomes that HTO is medical substitute to KA in active and young patients with $\mathrm{KO}[49]$.

\subsection{Open Wedge HTO}

Yokoyama et al. [50] recommended that impact of OWHTO emerged in three months and average period for healing was 6.3 months. This research evaluated 47 patients who undergone OWHTO treatment. Women and patients with high body mass index would like to have a much time to heal. Such facts are taken into consideration when selecting suitable method for surgery and have to be shared with patients with degenerative gonarthrosis of medial type since this could be main data for patients for deciding whether to undertake OWHTO.

Prospective interventional research in hospital was carried out on 30 patients of varus deformity osteoarthritis. All 30 patients were properly assessed the form of pre-operative surgical intervention in HTO was carried out and result was estimated using scoring system of knee society. This research has revealed that HTO for patients with UCO (Unicompartmental osteoarthritis) would reduce the pain as well as maximize the functional and knee score. Suitable selection of patient, exact types of osteotomy and exact surgical techniques are important for HTO success. It was also found that successful result of HTO is maintained for eight to ten years thus delay the necessity for conversion to arthroplasty of total knee. Thus HTO are suggested for treating the knee's degenerative arthritis among young patients [51].

OWHTO is an expanded method to treat the patients with MCO (medial compartment osteoarthritis) and VM (varus malalignment). For these patients, HRQL (health-related quality of life) are enhanced by adopting such procedure. 120 patients were selected for this research who undergone OWHTO without a graft of bone with the TomoFix ${ }^{\mathrm{TM}}$ plate. Mental component score for lower preoperative outcomes in minimized postoperative clinical result and extended time of inability for work after OWHTO. On the other hand, score of physical component exhibit comparable values to usual inhabitant already six months after OWHTO [52].

[33] [45] [46] stated that HTO is best suitable for treating the young patients. Age was found to be main factor for selection of HTO patient. Bonasia et al. [53] examined 99 OWHTOs patients and it was identified that age was main factor, probably failed operation was 5 times highest in patients aged greater than 56 years which indicate there must be necessity to again consider the range of age. Results are consistent with the findings of [45].

It was revealed that medial OWHTO would influence the patellofemoral joint (PJ). Some of the researchers have opined that medial OWHTO result in patella baja, thus lead to maximized pressure in patellofemoral contact [54] [55] [56]. In addition to these, some researchers have investigated about that impact of medial OWHTO on PJ with the help of arthroscopic assessment. It was found that overall decline in PJ at articular cartilage over time with the help of medial OWHTO [57] [58] [59] [60]. 
Moon et al. [61] examined over 92 patients with medical OWHTO and proceeding by assessment of $2^{\text {nd }}$-look arthroscopic. Patients were categorized into 2 groups. Comparative analysis was carried out with respect to measurements of arthroscopic, radiographic parameters and clinical scores among two groups. From the outcomes of clinical result, it was indicated overall enhancement from baseline to $2^{\text {nd }}$-look operation time, with no major variance between 2 groups. In radiographic parameters, no significant variances were found among two groups. Patellofemoral osteoarthritis in terms of radiographic grade in both groups indicated no statistical significant but shown development. When considering arthroscopic assessment, size of cartilage lesion on PJ maximized with time among two groups, whereas change degree over time among 2 groups were not significant statistically. As a result, no significant variance was seen among frequency in the grade of cartilage lesion progression in PJ among 2 groups. Medical OWHTO are responsible for osteoarthritis progression of $\mathrm{PJ}$ with respect to status of preexisting cartilage, without the link with following up at short-term in clinical outcomes.

Erquicia et al. [62] studied about patients who undergone surgery with Biplane OWHTO and minimum 2 years of follow-up were taken into consideration. 23 patients were considered with 33 months of follow-up. No alternations in lateral patellar tilt, slope of posterior tibial and patellar height were noticed. No patients were found with both clinical and radiological symptoms at joint of patellofemoral. OWHTO with tibial tubercle posterior and dihedral L-cut distal perfectly aligned axial malalignment with no modifications at posterior tibial slope and patella-femoral joint and give enhanced function at knee for minimal term follow-up. Clinical and radiographic outcomes pointed out that adopting such technique for treating varus malalignment and KO medial compartment in middle-aged and young persons with normal-to-low patellar height.

High EKAM (external knee adduction moment) is a replacement assessment of medial loading of knee, thus correlates greater with internal forces of medial contact in initial stance [63]. OWHTO minimizes initially elevated high level of EKAM which is minimal when compared with noticed control subjects [64] [65] [66].

Dragosloveanu et al. [67] determined that there was no significance between after slope of surgery tibial and preoperative varus whereas posterior inclination after HTO impacts the slope of tibial posterior at two years. Correction degree has strong impact over reduce or increase in slope of tibial posterior. A rise in tibial slope maximizes the flexion in the knee by 1.45 degree for each inclination degree. Moghtadaei et al. [68] evaluated the impact of proximal HTO on hip biomechanics. Cohort research was carried out fifty knees of thirty seven patients categorized into 2 groups of bilateral and unilateral surgeries from 2015 to 2016. Patients who operate on medical OWHTO were assessed. Outcomes from bilateral and unilateral HTO have shown that average of GT (greater trochanter) angle from head center of femoral and average knee varus angle was minimized. 
HTO influences GT and reasons for GT's downward replacement and thus reduce the arm of abductors moment, maximized force of hip joint reaction and shear force reduction on femoral neck.

In the research conducted by Yang et al. [69] reconstructed models of finite element with the help of models in artificial bone, plate of commercial bone \& locking screws in model of HTO. 6.5/8.0-mm pretensioned or $6.5-\mathrm{mm}$ cancellous screw of lag was practically added from opposite cortex to plateau of medial tibial. To simulate initial sit-to-stand and standing postures testing loads were adopted. Posteromedial tibial plateau (PTP)'s axial displacement shows loss of PTP in clinical notification and focuses on locking screws, plate in the bone and opposite screws were examined. Insertion of pretensioned screw of lag efficiently minimized the loss of reducing posteromedial when compared with model of HTO without insertion of opposite screw helps to sit-to-stand by 53 percent, $6.5-\mathrm{mm}$ lag screw assist to stand by 50.8 percent, $8.0-\mathrm{mm}$ lag screws helps in standing by 51.9 percent normalized by intact model performance. Stresses given on screws were less than corresponding plates of bone thus threat of breakage of screw are less. It was confirmed that insertion in the pretensioned opposite screw of lag is efficient and simple technique to enhance the structural stability in MOWHTO (medical open-wedge HTO). Clinical and biomechanical verification is needed for enhancing confidence of patient in this technique.

\subsection{Closed Wedge HTO}

Soleimanpour et al. [70] identified a statistically related difference between closed wedge HTO and OWHTO. It was clear that OWHTO was significant in operation length, duration of weight-bearing and return to normal lifestyle. Prognosis of single and integrated HTO with other procedures was studied. It was found that postoperative follow-up after 2 years, prognostic survival was best in terms of OWHTO when compared with CWHTO [71]. OWHTO minimized lateral thrust (LT) and varus movement on the other hand CWHTO does not minimize LT [65] [72].

Kim et al. [73] carried out meta-analysis to compare the survivorship longevity of OWHTO versus CWHTO. Time for survival was taken into consideration for conversion time to TKA. When survival rate were followed for 5 years were 95.1 percent in OWHTO and 93.9 percent in CWHTO. It was clear that 1.2 percent high survival rate was seen in OWHTO than CWHTO. Likewise when patients were followed for 10 years, survival rate for OWHTO were found to be 91.6 percent and CWHTO were found to be 85.4 percent. Even after 10 years follow-up, OWHTO had 6.2 percent higher survival rate than CWHTO. Not much difference were seen when analyzed for 5 year follow-up but analyzing survival rate for 10 years, OWHTOs was higher in terms of survival rate.

Huizinga et al. [74] conducted a research with 110 osteoarthritis patients with knee medial compartment with varus malalignment $\left(6^{\circ}-12^{\circ}\right)$ among persons aged 18 years are recruited for participating in controlled randomized trial. They 
are randomized to undertake a $\mathrm{HTO}$ with either CWHTO or combine technique of wedge osteotomy. Combined HTO changes avoid bone loss in metaphyseal tibial, reduce tibial condyle transposition and lessen patellar tendon after surgery, this is applicable for high correction case also. Clinical outcomes of combine HTO are effective. It was obvious from the analysis that when follow-up after one year of surgery, combined HTO technique had achieved more exactly what patient need during varus malalignment correction with less anatomical modification of proximal tibia.

\section{Discussion}

Table 1 depicts various techniques in HTO. HTO is important surgery in active and young people with KO medial compartment. From the review, it was noted that complication rates, correction loss and delayed union was high among patients whose graft was unused. Techniques of open wedge and closed wedge are adopted for KO patients. OWHTO is successful and safe option of treatment for varus deformity patients. When compared with CWHTO, OWHTO performs well in terms of survival rate and return back to normal life (Duivenvoorden et al., 2014) and Deie et al., 2014). At the same time, it could be noticed that when HTO performed above 50 years patients, success rate is less than young patients.

Table 1. Various techniques in HTO.

\begin{tabular}{|c|c|c|c|}
\hline S.No & Author and Year & Methodology & Findings \\
\hline 1 & $\begin{array}{l}\text { Malahias et al. } \\
\text { (2018) }\end{array}$ & $\begin{array}{l}\text { Patients with deficient varus angulated knee-anterior } \\
\text { cruciate ligament (ACL) require isolated HTO as well } \\
\text { as extra ACL reconstruction were reviewed }\end{array}$ & $\begin{array}{l}\text { ACL reconstruction and one stage HTO is efficient } \\
\text { and safe procedure to treat the patients who suffer } \\
\text { from symptomatic varus osteoarthritis to combine } \\
\text { with instability of anterior knee }\end{array}$ \\
\hline 2 & Yang et al. (2020) & $\begin{array}{l}6.5 / 8.0-\mathrm{mm} \text { pretensioned or } 6.5-\mathrm{mm} \text { cancellous screw } \\
\text { of lag was practically added from opposite cortex to } \\
\text { plateau of medial tibial }\end{array}$ & $\begin{array}{l}\text { Insertion in the pretensioned opposite screw of lag } \\
\text { is efficient and simple technique to enhance the } \\
\text { structural stability in MOWHTO }\end{array}$ \\
\hline 3 & Weiye et al. (2020) & $\begin{array}{l}\text { Male patient aged } 48 \text { years with KO occurred by } \\
\text { long-term varus of genu which outcome in both } \\
\text { knees pain, particularly in right knee }\end{array}$ & $\begin{array}{l}\text { Treating the KO patients with varus of genu, HTO } \\
\text { combination, regeneration of tissue in chronic } \\
\text { distraction and computer-assisted adjustment in } \\
\text { technology of external fixation have best impact on } \\
\text { correcting the deformity of genu varus and } \\
\text { recovery of minimal line of limb force }\end{array}$ \\
\hline 4 & Sarwar et al. (2019) & $\begin{array}{l}\text { Success rate and complication rate among patients } \\
\text { after HTO were reviewed }\end{array}$ & $\begin{array}{l}\text { HTO is efficient for reducing the pain and } \\
\text { function of knee improvement in patients } \\
\text { with knee's medial compartmental OA }\end{array}$ \\
\hline 5 & $\begin{array}{l}\text { Carvalho et al. } \\
(2016)\end{array}$ & $\begin{array}{l}174 \text { patients who underwent HTO are estimated after } \\
47.9 \text { days follow-up periods. Among them } 118 \\
\text { patients were male and } 56 \text { patients were female. } \\
\text { Age of the patients were from } 53 \text { to } 67 \text { years }\end{array}$ & $\begin{array}{l}\text { HTO permit patients to continue their physical } \\
\text { activities with symptomatic osteoarthritis of KO } \\
\text { medial compartment, outcome in enhancing clinical } \\
\text { conditions and as a result in their recreational } \\
\text { activities and every day working activities }\end{array}$ \\
\hline
\end{tabular}




\section{Continued}

6

Pannell et al. (2019)

7

Kumar et al. (2019)

Hoorntje et al.

(2019)

Yokoyama et al. (2016)

Ganeshsankar et al. (2017)
1576 procedures from 2000 to 2014, among these 358 procedures were changed to arthroplasty during ten years

Single centre and interventional research was performed on 60 patients were radiologically and clinically diagnosed as varusdeformity KO. Age of the patients was from 45 to 50 years. 23 patients were male and 37 patients were female

Patients selected are from sports. Patients were selected from age group between 18 and 70 years.

47 patients who undergone OWHTO treatment. 34 female patients and 13 male patients were included. Mean age is 59.8 years

All 30 patients were properly assessed the form of pre-operative surgical intervention in HTO was carried out and result was estimated using scoring system. Patients' age was between 45 years and 50 years. 10 patients were male and 20 patients were female

92 patients with medical OWHTO and proceeding by assessment of $2^{\text {nd }}$-look arthroscopic

Patients who undergone surgery with Biplane OWHTO and minimum 2 years of follow-up were taken into consideration. 23 patients ( 8 females and 15 males) were considered with 33 months of follow-up. Patients were selected from age 20.1 to 54.3 years

Statistically related difference between closed wedge HTO and OWHTO. Mean age is 67.2 years. 76 patients were male and 65 patients were female

Meta-analysis to compare the survivorship longevity of OWHTO versus CWHTO

110 osteoarthritis patients with knee medial compartment with varus malalignment $\left(6^{\circ}-12^{\circ}\right)$ among persons aged 18 years. Gender was not included in regression model
Long-term survival was seen among selected patients who undergone HTO

HTO must be suggested for degenerative arthritis treatment of knee in active, young patients for symptomatic enhancement and activity levels maintenance

It was identified that more than 8 patients out of 10 after HTO, return to sport and among them most of them RTO within six months

Women and patients with high body mass index would like to have a much time to heal

Successful result of HTO is maintained for eight to ten years thus delay the necessity for conversion to arthroplasty of total knee

Medical OWHTO are responsible for osteoarthritis progression of $\mathrm{PJ}$ with respect to status of preexisting cartilage, without the link with following up at short-term in clinical outcomes

Clinical and radiographic outcomes pointed out that adopting such technique for treating varus malalignment and $\mathrm{KO}$ medial compartment in middle-aged and young persons with normal-to-low patellar height

OWHTO was significant in operation length, duration of weight-bearing and return to normal lifestyle

OWHTOs was higher in terms of survival rate

when follow-up after one year of surgery, combined HTO technique had achieved more exactly what patient need during varus malalignment correction with less anatomical modification of proximal tibia

\section{Conclusion and Future Work}

Main intention of the research is to understand about significance of techniques associated with HTO. This research reviewed the techniques of HTO namely HTO, open wedge HTO, closed HTO. Patients who are suffering from knee arthritis, HTO assists to prevent or delay the requirement for total or partial replacement of knee to preserve damaged tissue of joint. HTO technique is mainly 
suitable for active and young patients with $\mathrm{KO}$. Age plays a main factor in success rate of HTO technique. It could be done in open wedge or closed wedge HTO. For some cases, surgery could be done in combined method (open wedge and closed wedge HTO). When compared with clinical outcomes of CWHTO and OWHTO, OWHTO performs well in reducing the pain, duration of weight-bearing and return back to normal life as soon as possible. This research is focused only about techniques and procedures related to HTO. This research generally reviews about the patients who underwent HTO procedure. Further this work could be extended by collecting data from patients who underwent HTO procedure.

\section{Conflicts of Interest}

The authors declare no conflicts of interest regarding the publication of this paper.

\section{Funding Source}

Funding is fully supported by Department of Orthopedic surgery, Zhongda Hospital affiliated to Southeast University.

\section{References}

[1] Kutzner, I., Heinlein, B., Graichen, F., Bender, A., Rohlmann, A., Halder, A.,, Beier, A. and Bergmann, G. (2010) Loading of the Knee Joint during Activities of Daily Living Measured in Vivo in Five Subjects. Journal of Biomechanics, 43, 2164-2173. https://doi.org/10.1016/j.jbiomech.2010.03.046

[2] Chen, Z., Zhang, X., Ardestani, M.M., Wang, L., Liu, Y., Lian, Q., He, J., Li, D. and Jin, Z. (2014) Prediction of in Vivo Joint Mechanics of an Artificial Knee Implant Using Rigid Multi-Body Dynamics with Elastic Contacts. Proceedings of the Institution of Mechanical Engineers, Part H: Journal of Engineering in Medicine, 228, 564-575. https://doi.org/10.1177/0954411914537476

[3] Fraysse, F., Arnold, J. and Thewlis, D. (2016) A Method for Concise Reporting of Joint Reaction Forces Orientation during Gait. Journal of Biomechanics, 49, 3538-3542. https://doi.org/10.1016/j.jbiomech.2016.08.005

[4] Jin, P.M and Holloway, E.S. (2013) The Young Osteoarthritic Knee: Dilemmas in Management. BMC Medicine, 11, 14. https://doi.org/10.1186/1741-7015-11-14

[5] Pereira, D., Ramos, E. and Branco, J. (2014) Osteoarthritis. Acta Médica Portuguesa, 28, 99-106. https://doi.org/10.20344/amp.5477

[6] Arya, R.K. and Vijay, J. (2013) Osteoarthritis of the Knee Joint: An Overview. IIACM, 14, 154-162.

[7] Hui, C., Salmon, L.J., Kok, A., Williams, H.A., Hockers, N., van der Tempel, W.M., Chana, R. and Pinczewski, L.A. (2011) Long-Term Survival of High Tibial Osteotomy for Medial Compartment Osteoarthritis of the Knee. The American Journal of Sports Medicine, 39, 64-70. https://doi.org/10.1177/0363546510377445

[8] Lee, S., Jung, K.A., Nam, C.H., Jung, S.H. and Hwang, S.H. (2010) The Short-Term Followup Results of Open Wedge High Tibial Osteotomy with Using an Aescula Open Wedge Plate and an Allogenic Bone Graft: The Minimum 1-Year Follow-up Results. Clinics in Orthopaedic Surgery, 2, 47-54.

https://doi.org/10.4055/cios.2010.2.1.47 
[9] Oh, C., Sung-Jung, K., Sung-Ki, P., Hee-June, K., Hee-Soo, K., Hwan-Sung, C., Park, B., Kim, S. and Ihn, J. (2011) Hemicallotasis for Correction of Varus Deformity of the Proximal Tibia Using a Unilateral External Fixator. Journal of Orthopaedic Science, 16, 44-50. https://doi.org/10.1007/s00776-010-0006-2

[10] Lespasio, M.J., Piuzzi, N.S., Husni, M.E., Muschler, F., Guarino, A.J. and Mont, A. (2017) Knee Osteoarthritis: A Primer. The Permanente Journal, 21, 16-183. https://doi.org/10.7812/TPP/16-183

[11] Spahn, G., Hofmann, G.O., von Engelhardt, L.V., Li, M., Neubauer, H. and Klinger, H.M. (2013) The Impact of a High Tibial Valgus Osteotomy and Unicondylar Medial Arthroplasty on the Treatment for Knee Osteoarthritis: A Meta-Analysis. Knee Surgery, Sports Traumatology, Arthroscopy, 21, 96-112.

https://doi.org/10.1007/s00167-011-1751-2

[12] Dahl, W.A., Robertsson, O., Lohmander, L.S. (2012) High Tibial Osteotomy in Sweden, 1998-2007. Acta Orthopaedica, 83, 1-5. https://doi.org/10.3109/17453674.2012.688725

[13] Badawy, M., Fenstad, A.M., Indrekvam, K., Havelin, L.I. and Furnes, O. (2015) The Risk of Revision in Total Knee Arthroplasty Is Not Affected by Previous High Tibial Osteotomy: A 15-Year Follow-Up of 32,476 Total Knee Arthroplasties in the Norwegian Arthroplasty Register. Acta Orthopaedica, 86, 734-739.

https://doi.org/10.3109/17453674.2015.1060402

[14] Price, A.J., Longino, D., Rees, J., Rout, R., Pandit, H., Javaid, K., et al. (2010) Are Pain and Function Better Measures of Outcome than Revision Rates after TKR in the Younger Patient? Knee, 17, 196-199. https://doi.org/10.1016/j.knee.2009.09.003

[15] Nam, D., Nunley, R.M. and Barrack, R.L. (2014) Patient Dissatisfaction Following Total Knee Replacement: A Growing Concern? The Bone \& Joint Journal, 96, 96-100. https://doi.org/10.1302/0301-620X.96B11.34152

[16] Liddle, A.D., Pandit, H., Judge, A. and Murray, D.W. (2015) Patient-Reported Outcomes after Total and Unicompartmental Knee Arthroplasty: A Study of 14,076 Matched Patients from the National Joint Registry for England and Wales. The Bone \& Joint Journal, 97, 793-801. https://doi.org/10.1302/0301-620X.97B6.35155

[17] Jones, G.G., Kotti, M., Wiik, A.V., Collins, R., Brevadt, M.J., Strachan, R.K., et al. (2016) Gait Comparison of Unicompartmental and Total Knee Arthroplasties with Healthy Controls. The Bone \& Joint Journal, 98, 16-21. https://doi.org/10.1302/0301-620X.98B10.BJJ.2016.0473.R1

[18] Fu, D., Li, G., Chen, K., Zhao, Y., Hua, Y. and Cai, Z. (2013) Comparison of High Tibial Osteotomy and Unicompartmental Knee Arthoplasty in the Treatment of Unicompartmental Osteoarthritis. The Journal of Arthroplasty, 28, 759-765. https://doi.org/10.1016/j.arth.2013.02.010

[19] Nha, K.W., Kim, H.J., Ahn, H.S. and Lee, D.H. (2016) Change in Posterior Tibial Slope after Open-Wedge and Closed-Wedge High Tibial Osteotomy: A Meta-Analysis. The American Journal of Sports Medicine, 44, 3006-3013. https://doi.org/10.1177/0363546515626172

[20] Preston, S., Howard, J., Naudie, D., Somerville, L. and McAuley, J. (2014) Total Knee Arthroplasty after High Tibial Osteotomy: No Differences between Medial and Lateral Osteotomy Approaches. Clinical Orthopaedics and Related Research, 472, 105-110. https://doi.org/10.1007/s11999-013-3040-5

[21] Kyung, H.S. (2016) High Tibial Osteotomy for Medial Knee Osteoarthritis. Knee Surgery \& Related Research, 28, 253-254. https://doi.org/10.5792/ksrr.16.253

[22] Sun, H., Zhou, L., Li, F. and Duan, J. (2017) Comparison between Closing-Wedge 
and Opening-Wedge High Tibial Osteotomy in Patients with Medial Knee Osteoarthritis: A Systematic Review and Meta-Analysis. The Journal of Knee Surgery, 30, 158-165. https://doi.org/10.1055/s-0036-1584189

[23] Schallberger, A., Jacobi, M., Wahl, P., Maestretti, G. and Jakob, R.P. (2011) High Tibial Valgus Osteotomy in Unicompartmental Medial Osteoarthritis of the Knee: A Retrospective Follow-Up Study over 13 - 21 Years. Knee Surg. Knee Surgery, Sports Traumatology, Arthroscopy, 19, 122-127. https://doi.org/10.1007/s00167-010-1256-4

[24] Seo, S., Kim, K., Seo, J., Kim, D., Kim, Y. and Lee, I. (2016) Complications and Short-Term Outcomes of Medial Opening Wedge High Tibial Osteotomy Using a Locking Plate for Medial Osteoarthritis of the Knee. Knee Surgery \& Related Research, 28, 289-296. https://doi.org/10.5792/ksrr.16.028

[25] Bonnin, M.P., Laurent, J.R., Zadegan, F., Badet, R., Archbold, H.A.P. and Servien, E. (2013) Can Patients Really Participate in Sport Aier High Tibial Osteotomy? Knee Surgery, Sports Traumatology, Arthroscopy, 21, 64-73. https://doi.org/10.1007/s00167-011-1461-9

[26] Felts, E., Parratte, S., Pauly, V., Aubaniac, J.M. and Argenson, J.N. (2010) Function and Quality of Life Following Medial Unicompartmental Knee Arthroplasty in Patients 60 Years of Age or Younger. Orthopaedics \& Traumatology: Surgery \& Research, 96, 861-867. https://doi.org/10.1016/j.otsr.2010.05.012

[27] Warme, B.A., Aalderink, K. and Amendola, A. (2011) Is There a Role for High Tibial Osteotomies in the Athlete? Sports Health, 3, 59-69. https://doi.org/10.1177/1941738109358380

[28] de Carvalho, L.H.J., Temponi, E.F., Soares, L.F., Gonçalves, M.B. and Costa, L.P. (2014) Physical Activity Aier Distal Femur Osteotomy for the Treatment of Lateral Compartment Knee Osteoarthritis. Knee Surgery, Sports Traumatology, Arthroscopy, 22, 1607-1611. https://doi.org/10.1007/s00167-012-2316-8

[29] Merchan, E. (2018) Does a Previous High Tibial Osteotomy Influence the Long-Term Function or Survival of a Total Knee Arthroplasty. Archives of Bone and Joint Surgery.

[30] Efe, T., Heyse, T.J., Boese, C., Timmesfeld, N., Fuchs Winkelmann, S., Schmitt, J., et al. (2010) TKA Following High Tibial Osteotomy versus Primary TKA: A Matched Pair Analysis. BMC Musculoskeletal Disorders, 11, 207. https://doi.org/10.1186/1471-2474-11-207

[31] Amendola, L., Fosco, M., Cenni, E. and Tigani, D. (2009) Knee Joint Arthroplasty after Tibial Osteotomy. International Orthopaedics, 34, 289-295. https://doi.org/10.1007/s00264-009-0894-y

[32] Meding, J.B., Wing, J.T. and Ritter, M.A. (2011) Does High Tibial Osteotomy Affect the Success or Survival of a Total Knee Replacement? Clinical Orthopaedics and Related Research, 469, 1991-1994. https://doi.org/10.1007/s11999-011-1810-5

[33] Niinimäki, T., Eskelinen, A., Ohtonen, P., Puhto, A.P., Mann, B.S. and Leppilahti, J. (2014) Total Knee Arthroplasty after High Tibial Osteotomy: A Registry-Based Case-Control Study of 1,036 Knees. Archives of Orthopaedic and Trauma Surgery, 134, 73-77. https://doi.org/10.1007/s00402-013-1897-0

[34] Erak, S., Naudie, D., MacDonald, S.J., McCalden, R.W., Rorabeck, C.H. and Bourne, R.B. (2011) Total Knee Arthroplasty Following Medial Opening Wedge Tibial Osteotomy: Technical Issues Early Clinical Radiological Results. Knee, 18, 499-504. https://doi.org/10.1016/j.knee.2010.11.002

[35] Malahias, M., Shahpari, O. and Kaseta, M. (2018) The Clinical Outcome of One-Stage 
High Tibial Osteotomy and Anterior Cruciate Ligament Reconstruction. A Current Concept Systematic and Comprehensive Review. Archives of Bone and Joint Surgery, 6, 161-168.

[36] Cao, Z., Mai, X., Wang, J., Feng, E. and Huang, Y. (2017) Unicompartmental Knee Arthroplasty vs High Tibial Osteotomy for Knee Osteoarthritis: A Systematic Review and Meta-Analysis. Journal of Arthroplasty, 33, 952-959.

https://doi.org/10.1016/j.arth.2017.10.025

[37] Takeuchi, R., Umemoto, Y., Aratake, M., Bito, H., Saito, I., Kumagai, K., Sasaki, Y., Akamatsu, Y., Ishikawa, H., Koshino, T. and Saito, T. (2010) A Mid-Term Comparison of Open Wedge High Tibial Osteotomy vs Unicompartmental Knee Arthroplasty for Medial Compartment Osteoarthritis of the Knee. Journal of Orthopaedic Surgery and Research, 5, 65. https://doi.org/10.1186/1749-799X-5-65

[38] Santoso, M.B. and Wu, L. (2017) Unicompartmental Knee Arthroplasty, Is It Superior to High Tibial Osteotomy in Treating Unicompartmental Osteoarthritis? A Meta-Analysis and Systemic Review. Journal of Orthopaedic Surgery and Research, 12, 50. https://doi.org/10.1186/s13018-017-0552-9

[39] Jeon, Y.S., Ahn, C.H. and Kim, M.K. (2017) Comparison of HTO with Articular Cartilage Surgery and UKA in Unicompartmental OA. Journal of Orthopaedic Surgery, 25, 1-6. https://doi.org/10.1177/2309499016684092

[40] Weiye, Z., Chunyou, W., Tao, Z., Mingjie, W., Zhao, L, Ningning, Z., Yuanhang, Z. (2020) Comprehensive Application of High Tibialoesteotomy, Chronic Distraction Tissue Regeneration, and Computer-Assisted External Fixation in the Treatment of Severe Knee Osteoarthrithis. Clinical Case Report.

[41] Sarwar, S., Lu, J., Marcella, C. and Ji, M.L. (2019) Indications and Clinical Outcomes of High Tibial Osteotomy: A Literature Review. Journal of Orthopedics and Muscular System, 2, 1007.

[42] Brouwer, R.W., Huizinga, M.R., Duivenvoorden, T., van Raaij, T., Verhagen, A., Zeinstra, B. and Verhaar, J. (2014) Osteotomy for Treating Knee Osteoarthritis. The Cochrane Database of Systematic Reviews, 12, CD004019. https://doi.org/10.1002/14651858.CD004019.pub4

[43] Carvalho, L., Soares, L., Goncalves, M., Costa, L., Franca, G., Costa, E. and Temponi, F. (2016) Physical Activity after High Tibial Osteotomy for Treatment of Medical Compartment Knee Osteoarthritis. Rheumatology: Current Research, 6, Article ID: 1000200. https://doi.org/10.4172/2161-1149.1000200

[44] Niinimaiki, T.T., Eskelinen, A., Mann, B.S., Junnila, M., Ohtonen, P. and Leppilahti, J. (2012) Survivorship of High Tibial Osteotomy in the Treatment of Osteoarthritis of the Knee: Finnish Registry-Based Study of 3195 Knees. The Journal of Bone and Joint Surgery, 94, 1517. https://doi.org/10.1302/0301-620X.94B11.29601

[45] Howells, N.R., Salmon, L., Waller, A., Scanelli, J. and Pinczewski, L.A. (2014) The Outcome at Ten Years of Lateral Closing-Wedge High Tibial Osteotomy: Determinants of Survival and Functional Outcome. The Bone \& Joint Journal, 96, 1491. https://doi.org/10.1302/0301-620X.96B11.33617

[46] Pascale, W., Luraghi, S., Perico, L., Pascale, V. (2011) Do Microfractures Improve High Tibial Osteotomy Outcome? Orthopedics, 34, e251-e255. https://doi.org/10.3928/01477447-20110526-06

[47] Pannell, C., Heidari, K., Mayer, E., Zimmerman, K., Heckmann, N., McKnight, B., Hill, J., Vangsness, C., Hatch, G. and Weber, A. (2019) High Tibial Osteotomy Survivorship: A Population Based Study. Orthopaedic Journal of Sports Medicine, 7, 1-7. https://doi.org/10.1177/2325967119890693

[48] Kumar, P., Sivanandan, H. and Manoharan, A.E. (2019) A Prospective Study of 
Functional Outcome of High Tibial Osteotomy. International journal of Orthopaedics Sciences, 5, 774-778. https://doi.org/10.22271/ortho.2019.v5.i3m.1625

[49] Hoorntje, A., Paul, P., Kuijer, F.M., Berbke, T., Ginneken, V., Koenraad, L.M., Rutger, C.I., Geenen, V., Kerkhoffs, M. and Heerwaardan, V. (2019) Prognostic Factors for Return to Sport after High Tibial Osteotomy: A Directed Acyclic Graph Approach. American Journal of Sports Medicine, 47, 1854-1862. https://doi.org/10.1177/0363546519849476

[50] Yokoyama, M., Nakamura, Y., Onishi, T., Hirano, K. and Doi, M. (2016) Healing Period after Open High Tibial Osteotomy and relAted Factors: Can We Really Say that It Is Long? Springerplus. https://doi.org/10.1186/s40064-016-1745-0

[51] Ganeshshankar, K., Praneshkumar, M. and Radhakrishnan, S. (2016) Functional Outcome of High Tibial Osteotomy Young Patients with Osteoarthritis. International Journal of Orthopaedics Sciences, 3, 72-74. https://doi.org/10.22271/ortho.2017.v3.i1b.11

[52] Ihle, C., Ateschrang, A., Grunwald, L., Stockle, U., Saier, T. and Schroter, S. (2016) Health-Related Quality of Life and Clinical Outcomes Following Medial Open Wedge High Tibial Osteotomy: A Prospective Study. BMC Musculoskelet Disorder, 17, 215. https://doi.org/10.1186/s12891-016-1076-x

[53] Bonasia, D.E., Dettoni, F., Sito, G., Blonna, D., Marmotti, A., Bruzzone, M., Castoldi, F. and Rossi, R. (2014) Medial Opening Wedge High Tibial Osteotomy for Medial Compartment Overload/Arthritis in the Varus Knee: Prognostic Factors. The American Journal of Sports Medicine, 42, 690. https://doi.org/10.1177/0363546513516577

[54] Javidan, P., Adamson, G.J., Miller, J.R., Durand, P.J., Dawson, P.A., Pink, M.M. and Lee, T.Q. (2013) The Effect of Medial Opening Wedge Proximal Tibial Osteotomy on Patellofemoral Contact. The American Journal of Sports Medicine, 41, 80-86. https://doi.org/10.1177/0363546512462810

[55] Bin, S.I., Kim, H.J., Ahn, H.S., Rim, D.S. and Lee, D.H. (2016) Changes in Patellar Height after Opening Wedge and Closing Wedge High Tibial Osteotomy: A Meta-Analysis. Arthroscopy, 32, 2393-2400. https://doi.org/10.1016/j.arthro.2016.06.012

[56] Yang, J.H., Lee, S.H., Nathawat, K.S., Jeon, S.H. and Oh, K.J. (2013) The Effect of Biplane Medial Opening Wedge High Tibial Osteotomy on Patellofemoral Joint Indices. Knee, 20, 128-132. https://doi.org/10.1016/j.knee.2012.09.019

[57] Kim, J., Kim, H. and Lee, D. (2017) Survival of Opening versus Closing Wedge High Tibial Osteotomy: A Meta-Analysis. Scientific Reports. https://doi.org/10.1038/s41598-017-07856-8

[58] Tanaka, T., Matsushita, T., Miyaji, N., Ibaraki, K., Nishida, K., Oka, S., Araki, D., Kanzaki, N., Hoshino, Y., Matsumoto, T. and Kuroda, R. (2019) Deterioration of Patellofemoral Cartilage Status after Medial Open-Wedge High Tibial Osteotomy. Knee Surgery, Sports Traumatology, Arthroscopy, 27, 1347-1354. https://doi.org/10.1007/s00167-018-5128-7

[59] Goshima, K., Sawaguchi, T., Shigemoto, K., Iwai, S., Nakanishi, A. and Ueoka, K. (2017) Patellofemoral Osteoarthritis Progression and Alignment Changes after Open-Wedge High Tibial Osteotomy Do Not Affect Clinical Outcomes at Mid-Term Follow-Up. Arthroscopy, 33, 1832-1839. https://doi.org/10.1016/j.arthro.2017.04.007

[60] Yoon, T.H., Choi, C.H., Kim, S.J., Kim, S.H., Kim, N.H. and Jung, M. (2019) Effect of Medial Open-Wedge High Tibial Osteotomy on the Patellofemoral Joint According to Postoperative Realignment. The American Journal of Sports Medicine, 
47, 1863-1873. https://doi.org/10.1177/0363546519851096

[61] Moon, H., Choi, C., Jung, M., Park, S., Lee, D., Shin, J. and Kim, S. (2019) The Effect of Medical Open Wedge High Tibial Osteotomy on the Patellofemoral Joint: Comparative Analysis According to the Pre-Existing Cartilage Status. BMC Musculoskeletal Disorders. https://doi.org/10.1186/s12891-019-2989-y

[62] Erquicia, J., Gelber, P., Perelli, S., Ibanez, F., Ibanez, M., Pelfort, X. and Monllau, J. (2016) Biplane Opening Wedge High Tibial Osteotomy with a Distal Tuberosity Osteotomy, Radiological and Clinical Analysis with Minimum Follow-Up of 2 Years. Journal of Experimental Orthopaedics, 6, 10. https://doi.org/10.1186/s40634-019-0176-6

[63] Kutzner, I., Trepczynski, A., Heller, M.O. and Bergmann, G. (2013) Knee Adduction Moment and Medial Contact Force-Facts about Their Correlation during Gait. PLOS ONE, 8, e81036. https://doi.org/10.1371/journal.pone.0081036

[64] Lind, M., McClelland, J., Wittwer, J.E., Whitehead, T.S., Feller, J.A. and Webster, K.E. (2013) Gait Analysis of Walking before and after Medial Opening Wedge High Tibial Osteotomy. Knee Surgery, Sports Traumatology, Arthroscopy, 21, 74-81. https://doi.org/10.1007/s00167-011-1496-y

[65] Deie, M., Hoso, T., Shimada, N., Iwaki, D., Nakamae, A., Adachi, N. and Ochi, M. (2014) Differences between Opening versus Closing High Tibial Osteotomy on Clinical Outcomes and Gait Analysis. Knee, 21, 1046-1051. https://doi.org/10.1016/j.knee.2014.04.007

[66] Marriott, K., Birmingham, T.B., Kean, C., Hui, C., Jenkyn, T. and Giffin, J. (2015) Five-Year Changes in Gait Biomechanics after Concomitant High Tibial Osteotomy and ACL Reconstruction in Patients with Medial Knee Osteoarthritis. The American Journal of Sports Medicine, 43, 2277-2285. https://doi.org/10.1177/0363546515591995

[67] Dragosloveanu, S., Cristea, S. and Dragosloveanu, C. (2014) The Effect of High Tibial Osteotomy on the Posterior Tibial Slope. Maedica Journal of Clinical Medicine, 9, 173-178.

[68] Moghtadaei, M., Yeganeh, A., Boddouhi, B., Ataee, A., Farahini, H. and Otoukesh, B. (2017) Effect of High Tibial Osteotomy on Hip Biomechanics in Patients with Genu Varum: A Prospective Cohort Study. International Medicine and Applied Science, 9, 94-99. https://doi.org/10.1556/1646.9.2017.20

[69] Yang, J., Chen, C. and Lee, K. (2020) Benefits of Opposite Screw Insertion Technique in Medical Open-Wedge High Tibial Osteotomy: A Virtual Biomechanical Study. Journal of Orthopaedic Translation, 20, 31-36. https://doi.org/10.1016/j.jot.2019.06.004

[70] Soleimanpour, J., Elmi, A., Jafari, M.A. and Goldust, M. (2013) Comparison of Genu Varum Treating Results Using Open and Closed Wedge High Tibial Osteotomy. Pakistan Journal of Biological Sciences, 16, 686. https://doi.org/10.3923/pjbs.2013.686.691

[71] Harris, J.D., Mcneilan, R., Siston, R.A. and Flanigan, D.C. (2013) Survival and Clinical Outcome of Isolated High Tibial Osteotomy and Combined Biological Knee Reconstruction. Knee, 20, 154. https://doi.org/10.1016/j.knee.2012.12.012

[72] Duivenvoorden, T., Brouwer, R.W., Baan, A., Bos, P.K., Reijman, M., Zeinstra, B. and Verhaar, J.A. (2014) Comparison of Closing-Wedge and Opening-Wedge High Tibial Osteotomy for Medial Compartment Osteoarthritis of the Knee: A Randomized Controlled Trial with a Six-Year Follow-Up. The Journal of Bone and Joint Surgery, 96, 1425. https://doi.org/10.2106/JBJS.M.00786 
[73] Kim, K.I., Kim, D.K., Song, S.J., Lee, S.H. and Bae, D.K. (2017) Medial Open-Wedge High Tibial Osteotomy May Adversely Affect the Patellofemoral Joint. Arthroscopy, 33, 811-816. https://doi.org/10.1016/j.arthro.2016.09.034

[74] Huizinga, R., Brouwer, W. and Raaji, M. (2014) High Tibial Osteotomy: Closed Wedge versus Combined Wedge Osteotomy. BMC Musculoskeletal Disorders. https://doi.org/10.1186/1471-2474-15-124 